\title{
PILOT TESTS AND FOULING IDENTIFICATION IN THE ULTRAFILTRATION OF MODEL OILY AND SALINE WASTEWATERS
}

\section{BADANIA PILOTOWE I IDENTYFIKACJA FOULINGU W ULTRAFILTRACJI MODELOWYCH WÓD ZAOLEJONYCH I ZASOLONYCH}

\begin{abstract}
This paper evaluates ceramic membrane performance and fouling mechanisms in the ultrafiltration of model oil-in-water solutions with addition of $\mathrm{NaCl}$. First, the work estimated the effect of main process parameters, i.e. transmembrane pressure, cross-flow velocity and $\mathrm{NaCl}$ content in the feed on oil rejection and permeate flux using $2^{3}$ experimental design. The ultrafiltration experiments were carried out using pilot installation with commercial tubular ceramic $300 \mathrm{kDa}$ membrane. Ultrafiltration data obtained using experimental design technique was used to determine the regression coefficients of polynomial equations. These equations give information on non-conjugated as well as conjugated effects of two operating parameters and one feed parameter on ceramic membrane performance in ultrafiltration process of model oil-in-water-NaCl solutions. Moreover, these equations can help to determine optimal conditions for ultrafiltration process from the point of view of membrane permeability and selectivity. Next, ultrafiltration results were analyzed using resistance-in- series model. It was found that the process is membrane resistance limited. It was also stated that, resistance caused by reversible fouling is greater than irreversible fouling resistance. Finally, pore blocking models based on modified Hermia`s equation were used to determine membrane fouling mechanism responsible for permeate flux decline with ultrafiltration time. In investigated system ceramic membrane fouling was caused by complete and intermediate pore blocking mechanisms.
\end{abstract}

Keywords: ceramic membranes, fouling mechanism, ultrafiltration, oily and saline water emulsion

\section{Introduction}

Oily wastewaters as a different mixtures of oils, lubricants, salt and other chemical compounds are generated from diverse industrial sources including gas and oil production. Waste streams from onshore and offshore oil and gas operations are among the largest

\footnotetext{
${ }^{1}$ Faculty of Mechanics, Maritime University of Szczecin, ul. Wały Chrobrego 1-2, 70-500 Szczecin, Poland

${ }^{2}$ Faculty of Process and Environmental Engineering, Lodz University of Technology, ul. Wólczańska 213, 90-924 Łódź, Poland

${ }^{3}$ Faculty of Engineering and Economics of Transport, Maritime University of Szczecin, ul. Henryka Pobożnego 11, 70-507 Szczecin, Poland

${ }^{4}$ Faculty of Maritime Technology and Transport, Westpomeranian University of Technology, ul. Piastów 41, 71-065, Szczecin, Poland

*Corresponding author: k.cwirko@am.szczecin.pl
} 
sources of oily wastewaters. The oil content of these waste streams comes to $1000 \mathrm{ppm}$, and causes they must be treated for both the recycling process and the discharge into the environment $[1,2]$. Very complex composition of oily wastewater causes the removal of oil and other contaminants to a level compatible with the requirements in a single separation process to be insufficient [3]. Treatment technologies employed for such waste streams are the multistage ones $[4,5]$. In the hybrid technologies there were widely applied pressure membrane processes such as MF (microfiltration), UF (ultrafiltration) NF (nanofiltration) and RO (reverse osmosis) that were based primarily on ceramic membranes, characterized by high chemical and thermal resistance $[6,7]$. The main advantage of the use of membrane separation techniques is the ability to achieve a treated stream (permeate) meeting the environmental requirements and significantly reduced, compared to the waste stream undergoing the treatment concentrated stream (retentate), which must then be utilized at the ship or on land [8,9]. However, such membrane separation appear to have several drawbacks in treating the feed water containing different chemical substances and organic matter and to be susceptible to fouling [10].

In general, membrane fouling can be described as a reduction in membrane permeability as a result of the flow resistance appearing due to pore blocking, concentration polarization and cake formation [11]. Membrane permeability declines due to the accumulation of foulants on the membrane surface or within the membrane pores [12]. Moreover, it turned out that fouling mechanism depends mainly on the electrostatic interactions between particles but also between a particles and the membrane. On the other hand, the long term effects of membrane fouling may lead to irreversible blockage of the membrane and a reduction in the membrane lifetime [13]. To maintain the technical and economic viability of a membrane process, membrane fouling should be kept to a minimum [14].

In the literature, there are many papers on the application of membrane processes and polymeric and inorganic membranes for both oily wastewater and industrial wastewaters treatment $[15,16]$. Some of these papers deal with membrane production and modifications of membrane surface [17]. Reported research are for mostly focused on treatment of wastewater from the petrochemical and refinery industry [18] as well as of oily streams generated on-board, bilge water and ballast water $[19,20]$. Authors of the papers focus primarily on the analysis of the impact of the most important operating parameters like transmembrane pressure, feed velocity over the surface of the membrane, oil concentration in the feed, $\mathrm{pH}$ [21] or other feed components on performance of membrane process and oil removal efficiency. Only few papers analyzed the influence of the salt content [22, 23].

The industrial wastewater containing oil may also include a large amount of different salts, up to $300000 \mathrm{ppm}$ [24]. The main problem reported by the authors is that high salt concentration causes a significant decrease in removal of the other pollutants. However, some researchers are focused on the rejection from wastewater. Despite the high concentration of salts, the oil rejection coefficient ranges from 98 to $99 \%$ [24].

The salinity impact on membrane fouling using biofilm membrane bioreactors (MBR) in treatment of oily wastewater is often examined by researchers. According to this research, the increasing salt concentration might be a dominant factor causing membrane fouling due to the surface charge effect on particles and the surface of the membrane [25]. Other authors dealt with the influence of salinity on different factors [26]. In the conclusions the authors state that salt concentration affects the biodegradation of dissolved organic matters significantly. 
The ultrafiltration process of model oil-water- $\mathrm{NaCl}$ emulsion using ceramic tubular membrane was investigated from the point of view of the highest permeate flux and high oil rejection. For this purpose the ultrafiltration tests were carried out in accordance with the procedure of experimental design of $2^{3}$ type. Experiments were performed under different ultrafiltration operating parameters at two different levels, i.e.: cross-flow velocity, transmembrane pressure and $\mathrm{NaCl}$ concentration in the feed. The scope of the study included: 1. analysis of effect of main ultrafiltration process parameters on the membrane permeability and selectivity; 2. transport resistance analysis with applying resistance-in-series model; 3. identification of fouling mechanism using pore blocking models.

\section{Theoretical background}

\section{Experimental design $2^{3}$}

The experimental design can be successfully used in studies related to wastewater treatment using membrane techniques [27].

Based on two-level experimental design, the nonlinear object can be approximated by nonlinear regression function:

$$
y_{i}=f\left(x_{1}, \ldots, x_{n}\right)
$$

where $x_{1} \ldots x_{n}$ are independent variables and $y_{i}$ are responses.

For the analyzed membrane system, three independent variables, $x_{1}, x_{2}, x_{3}$ and two levels, $+1,-1$ are presented in Table 1 . The total number of experiments results from applied plan of $2^{3}=8$. The cross-flow velocity (CFV), transmembrane pressure (TMP) and salt content in the feed solution $\left(C_{\mathrm{NaCl}}\right)$ were chosen as independent variables $x_{1}, x_{2}, x_{3}$.

Table 1

$2^{3}$ experimental design matrix with standardized and real values of independent variables

\begin{tabular}{|c|c|c|c|c|}
\hline Independent variables, & \multicolumn{3}{|c|}{ Level } & \multirow{2}{*}{ Interval, $\boldsymbol{I}_{\boldsymbol{j}}$} \\
\cline { 2 - 4 } standardized (real) & $\mathbf{- 1}$ & $\mathbf{0}$ & $\mathbf{+ 1}$ & \\
\hline$x_{1}-\mathrm{CFV}[\mathrm{m} / \mathrm{s}]$ & 4.0 & 0.10 & 1.00 & 0.50 \\
$x_{2}-\mathrm{TMP}[\mathrm{MPa}]$ & 4.5 & 0.15 & 2.25 & 0.50 \\
$x_{3}-\mathrm{NaCl}$ concentration in the feed [\%] & 5.0 & 0.20 & 3.50 & 1.25 \\
\hline
\end{tabular}

In order to find the effect of independent variables on response, the polynomial equations can be used $[27,28]$. In this work steady-state permeate flux $J_{S S}\left[\mathrm{~m}^{3} /\left(\mathrm{m}^{2} \cdot \mathrm{s}\right)\right]$ and rejection of oil $r[-]$ are responses to process variables.

To be able to describe and compare responses as a function of process variables it is necessary to normalize them according to equation:

$$
x_{j z}=\frac{\left(x_{j}-x_{j 0}\right)}{I_{j}}
$$

where $x_{j z}$ is the standardized value of independent variable, $x_{j}$ the real value of inlet variable, $x_{j 0}$ the value at level 0 , and $I_{j}$ the variation interval.

The final equations using standardized of independent variables representing $J_{S S}$ and $r$ are presented by polynomial (3) and (4) which are usually used in to $2^{3}$ plan of experiments; 


$$
\begin{aligned}
& J_{S S}=f_{1}\left(x_{1 z}, x_{2 z}, x_{3 z}\right)=b_{0}+b_{1} x_{1 z}+b_{2} x_{2 z}+b_{3} x_{3 z} \\
& +b_{12} x_{1 z} x_{2 z}+b_{13} x_{1 z} x_{3 z}+b_{23} x_{2 z} x_{3 z}+b_{123} x_{1 z} x_{2 z} x_{3 z} \\
& r=f_{1}\left(x_{1 z}, x_{2 z}, x_{3 z}\right)=a_{0}+a_{1} x_{1 z}+a_{2} x_{2 z}+a_{3} x_{3 z} \\
& +a_{12} x_{1 z} x_{2 z}+a_{13} x_{1 z} x_{3 z}+a_{23} x_{2 z} x_{3 z}+a_{123} x_{1 z} x_{2 z} x_{3 z}
\end{aligned}
$$

The regression coefficients of Eqs. (3) and (4) were calculated by means of experimental data.

\section{Resistance-in-series model}

The resistance-in-series model has been commonly used to relate transmembrane pressure and permeation flux in the membrane separation process e.g. [29]:

$$
J_{S S}=\frac{\mathrm{TMP}}{\mu R_{T}}
$$

where: $J_{S S}$ - steady state permeate flux $\left[\mathrm{m}^{3} /\left(\mathrm{m}^{2} \mathrm{~s}\right)\right], R_{T}$ - total resistance $\left[\mathrm{m}^{-1}\right], \mu$ - permeate viscosity $[\mathrm{Pa} \cdot \mathrm{s}]$.

Total resistance $R_{T}$ is the sum of membrane resistance $R_{M}$ and fouling resistance $R_{F}$ :

$$
J_{S S}=\frac{\mathrm{TMP}}{\mu\left(R_{M}+R_{F}\right)}
$$

where $R_{M}$ is a membrane resistance $\left[\mathrm{m}^{-1}\right]$ and $R_{F}$ is a resistance caused by fouling $\left[\mathrm{m}^{-1}\right]$.

Resistance of fouling can be presented as the sum of the resistance of reversible fouling $R_{R F}$ and the resistance of irreversible resistance $R_{I F}$ :

$$
J_{S S}=\frac{\mathrm{TMP}}{\mu\left(R_{M}+R_{R F}+R_{I F}\right)}
$$

The sum of membrane resistance and resistance of irreversible fouling $\left(R_{M}+R_{I F}\right)$ is possible to calculate when after oil emulation in saline water UF the membrane is tested again with water only:

$$
J_{W 2}=\frac{\mathrm{TMP}}{\mu\left(R_{M}+R_{I F}\right)}
$$

Irreversible resistance $R_{I F}$ can be obtained:

$$
R_{I F}=\frac{\mathrm{TMP}}{\mu J_{W}}-R_{M}
$$

where $J_{W}$ is water flux before UF process $\left[\mathrm{m}^{3} /\left(\mathrm{m}^{2} \cdot \mathrm{s}\right)\right]$.

Finally, the reversible resistance $R_{R F}$ can be calculated:

$$
R_{R F}=R_{T}-R_{M}-R_{I F}
$$

Before each process of ultrafiltration, pure water flux through clean membrane $J_{W 1}$ $\left[\mathrm{m}^{3} /\left(\mathrm{m}^{2} \mathrm{~s}\right)\right]$ can be measured with distilled water. Directly after each ultrafiltration test, the value of distilled water flux $J_{W 2}\left[\mathrm{~m}^{3} /\left(\mathrm{m}^{2} \mathrm{~s}\right)\right]$ can be determined in order to estimate irreversible fouling, $R_{I F}$ (Eq. (9)). Then the UF membrane module and the installation can be chemically cleaned up, following the procedure recommended by the manufacturer.

\section{Membrane fouling models}

During the process of ultrafiltration of oil-in-water emulsions the particles of oil and salt carried by the liquid towards the membrane and then deposit on the membrane surface 
(cake formation mechanism) or block the pores of the membrane (pore blocking mechanism). As a result the filtration resistance is increasing while the filtration stream is decreasing during time. To describe the blocking phenomena in the investigated system, four models of membrane fouling have been used (Fig. 1).

a)

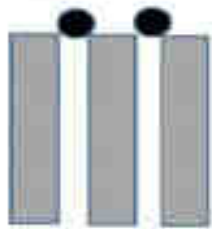

c)

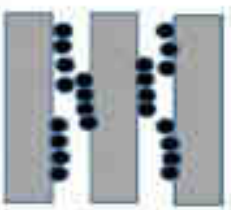

b)

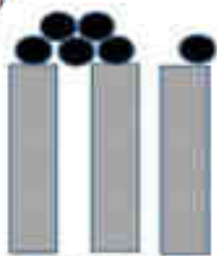

d)

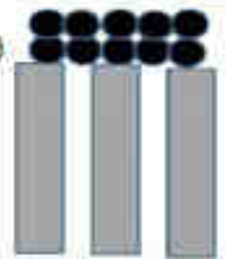

Fig. 1. Graphic presentation of pore blocking models: a) complete blocking; b) internal pore blocking; c) intermediate pore blocking; d) cake formation; based on [30]

Table 2 shortly describes all considered pore blocking mechanisms [31, 32].

Membrane fouling models description for cross-flow ultrafiltration

\begin{tabular}{|c|c|c|}
\hline $\begin{array}{c}\text { Membrane fouling } \\
\text { mechanism }\end{array}$ & $n$ & Description \\
\hline Complete pore blocking & 2 & $\begin{array}{l}\text { Blocking the entrances of membrane pores by particles; } \\
\text { the filtration resistance increasing with the decrease of number of } \\
\text { membrane pores }\end{array}$ \\
\hline Internal pore blocking & 1.5 & $\begin{array}{l}\text { Deposition or adsorption of microsolutes on the pore walls; } \\
\text { the decrease in pore volume }\end{array}$ \\
\hline $\begin{array}{l}\text { Intermediate pore } \\
\text { blocking }\end{array}$ & 1 & Occlusion of pores by particles with particle superimposition \\
\hline Cake formation & 0 & $\begin{array}{c}\text { Deposition of particles larger than the membrane pore size onto } \\
\text { the membrane surface. Cake resistance is proportional to the } \\
\text { cumulative filtered volume }\end{array}$ \\
\hline
\end{tabular}

To identify the fouling mechanism during the ultrafiltration process of model oil-in-water solutions, the mathematical model which describes flux decline with time can be used [33, 34]:

$$
\frac{d^{2} t}{d V^{2}}=k\left(\frac{d t}{d v}\right)^{n}
$$


where: $t$ - time [s], $v$ - permeate volume per membrane surface area $\left[\mathrm{m}^{3}\right], k$ and $n$ phenomenological coefficient and general index, respectively, both depending on the fouling mechanism.

This Hermia's model based on constant-pressure dead-end filtration can be modified for cross-flow filtration as follows [31]:

$$
\frac{d J}{d t}=-k\left(J-J_{S S}\right)^{2-n}
$$

In equation (12), the terms $J$ and $J_{S S}$ mean permeate flux and steady-state permeate flux, respectively.

Moreover, this equation can be transformed into forms describing four different membrane fouling mechanisms (Eqs. (13)-(16), Table 2). Equation (13) describes the complete pore blocking mechanism $(n=2)$, in which particles deposit on the membrane surface and block the membrane pores [31]:

$$
J=J_{S S}+\left(J_{0}-J_{S S}\right) e^{\left(-k_{2} t\right)}
$$

where: $J_{0}$ - initial permeate flux at time $t=0, k_{2}$ - kinetic coefficient [1/s].

When during the process of ultrafiltration, the material is absorbed on pore wall, the membrane fouling is caused by internal pore blocking mechanism $(n=1.5)$ and equation takes the form [32]:

$$
\frac{1}{J^{1 / 2}}=\frac{1}{J_{0}^{1 / 2}}+k_{1.5} t
$$

where $k_{1.5}$ - kinetic coefficient $\left[\mathrm{m} /\left(\mathrm{m}^{1.5} \mathrm{~s}^{0.5}\right)\right]$.

Intermediate pore blocking mechanism $(n=1)$, where particles settle on another arrived previously can be described as [21]:

$$
k_{1} t=\frac{1}{J_{S S}} \ln \left(\frac{J}{J_{0}} \cdot \frac{\left(J_{0}-J_{S S}\right)}{\left(J-J_{S S}\right)}\right)
$$

where $k_{1}$ - kinetic coefficient $\left[\mathrm{m}^{2} / \mathrm{m}^{3}\right]$.

As the cake formation mechanism $(n=0)$ is taking into account, some pores are blocking and there is no space for direct hindering the membrane area [31]. Then the equation takes the form:

$$
k_{0} t=\frac{1}{J_{S S}^{2}}\left[\ln \left(\frac{J_{0}}{J} \cdot \frac{\left(J_{0}-J_{S S}\right)}{\left(J-J_{S S}\right)}\right)\right]-J_{S S}\left(\frac{1}{J}-\frac{1}{J_{0}}\right)
$$

where $k_{0}$ - kinetic coefficient $\left[\left(\mathrm{m}^{2} / \mathrm{m}^{3}\right)^{2} \mathrm{~s}\right]$.

\section{Experimental}

\section{Materials and methods}

Ultrafiltration tests were performed with a use of pilot installation equipped with commercial 23-channel ceramic membrane with a cut-off $300 \mathrm{kDa}$ under defined process conditions (temperature $20{ }^{\circ} \mathrm{C}$, oil concentration in the feed $500 \mathrm{ppm}$ ). Some characteristic features of the membrane used for experiments are shown in Table 3. 
Model solutions in an amount of $10 \mathrm{dm}^{3}$ were prepared as an oil in water solution with $\mathrm{NaCl}$, at a concentration of 1 and $3.5 \%$. An oil-water emulsion was prepared using ultrasonic processor VCX-500 (Sonics) at the following operating parameters: frequency of $20 \mathrm{kHz}$, the vibration amplitude of peak-to-peak resonator: $124 \mu \mathrm{m}$, resonator diameter $13 \mathrm{~mm}$, temperature $22{ }^{\circ} \mathrm{C}$, scattering time $5 \mathrm{~s}$, oil injection directly into the resonator a distance approx. $5 \mathrm{~mm}$, power density in the injection zone of about $20 \mathrm{~W} / \mathrm{cm}^{2}$. Hydraulic oil HYDROL L-HL 46 (Orlen) was used in the homogenization process, at a concentration of $500 \mathrm{ppm}$ employing also a pipette HTL V3 possessing volume of $1 \mathrm{~cm}^{3}$ and interchangeable tips. The oil HYDROL L-HL 46 used for low and medium-loaded systems of power transmission for hydraulic control of devices with hydrostatic drive and was chosen as an oil for different purposes. After completion of the emulsion, in each case immediately proceeded to run the ultrafiltration test in order to maintain the structure of prepared solutions. The installation worked in a mode with recirculation of retentate and permeate, sampling was carried out only for measurements. Moreover, before starting the ultrafiltration tests a calibration curve for turbidity was performed.

Characteristics of ceramic membrane used for ultrafiltration experiments (Source: info TAMI)

\begin{tabular}{|c|c|}
\hline Cut-off $[\mathrm{kDa}]$ & 300 \\
\hline Material & $\mathrm{TiO}_{2} / \mathrm{ZrO}_{2}$ \\
\hline Number of channels & 23 \\
\hline Hydraulic diameter of membrane channel [m] & $3.5 \cdot 10^{-3}$ \\
\hline Length $[\mathrm{m}]$ & 1.178 \\
\hline Filtration area $\left[\mathrm{m}^{2}\right]$ & 0.35 \\
\hline Bursting pressure $[\mathrm{MPa}]$ & $>9.0$ \\
\hline Operating pressure $[\mathrm{MPa}]$ & $\max .1 .0$ \\
\hline Chemical resistance & $\mathrm{pH} \mathrm{0-14}$ \\
\hline Permeability for water $\left[\mathrm{dm}^{3} /\left(\mathrm{h} \mathrm{m}^{2}\right) \cdot 10^{5} \mathrm{~Pa}\right]$ & $450-500$ \\
\hline Process temperature & $<350^{\circ} \mathrm{C}$ \\
\hline Steam sterilization & $121{ }^{\circ} \mathrm{C}-30 \mathrm{~min}$ \\
\hline Oxidative sterilization & yes \\
\hline
\end{tabular}

At a course of each ultrafiltration run samples of feed $(\mathrm{F})$, permeate $(\mathrm{P})$ and retentate (R) were collected at specified time intervals. The duration of each experiment was 60 minutes. In each sample, the value of turbidity was determined (TN-100, Eutech Instruments). Based on turbidity measurements the oil retention coefficient, $r$ [-] was calculated:

$$
r=1-\frac{C_{P}}{C_{R}}
$$

where $C_{P}$ and $C_{R}$ - the oil concentration [ppm] in permeate and retentate respectively.

The permeate flux $J\left[\mathrm{~m}^{3} /\left(\mathrm{m}^{2} \mathrm{~s}\right)\right]$ was calculated using the volume of permeate per membrane area, $V_{p}\left[\mathrm{~m}^{3}\right]$ collected during the time $t[\mathrm{~s}]$ :

$$
J=\frac{V_{P}}{t \cdot S}
$$

where $S$ - membrane filtration area $\left[\mathrm{m}^{2}\right]$. 


\section{Results and discussion}

\section{Effect of operating parameters using $2^{3}$ factorial experimental design}

The detailed analysis for the experimental results, based on $2^{3}$ factorial experimental design matrix is shown in Table 4.

Using experimental data presented in Table 4, the regression coefficients $b_{i}$ and $a_{i}$ of the polynomial equations (3), (4) are evaluated and presented in Table 5.

Table 4

Experimental results of steady-state permeate flux $J_{S S}$ and oil rejection $r$ with independent standardized variables $x_{1 z}, x_{2 z}, x_{3 z}$, and real variables $\mathrm{CFV}, \mathrm{TMP}, C_{\mathrm{NaCl}}$

\begin{tabular}{|c|c|c|c|c|c|c|c|c|}
\hline $\mathbf{E x p .}$ & $\begin{array}{c}\mathbf{C F V} \\
{[\mathbf{m} / \mathbf{s}]}\end{array}$ & $\boldsymbol{x}_{\mathbf{1 z}}$ & $\begin{array}{c}\text { TMP } \\
{[\mathbf{M P a}]}\end{array}$ & $\boldsymbol{x}_{\mathbf{2 z}}$ & $\begin{array}{c}\boldsymbol{C}_{\mathbf{N a C l}} \\
{[\boldsymbol{\%}]}\end{array}$ & $\boldsymbol{x}_{\mathbf{3 z}}$ & $\begin{array}{c}\boldsymbol{J}_{\boldsymbol{S S}} \\
{\left[\mathbf{1 0}^{-\mathbf{5}}\left(\mathbf{m}^{\mathbf{3}} /\left(\mathbf{m}^{\mathbf{2}} \mathbf{s}\right)\right]\right.}\end{array}$ & $\boldsymbol{r}[-]$ \\
\hline 1. & 4 & -1 & 0.1 & -1 & 1 & -1 & 7.55 & 0.974 \\
\hline 2. & 5 & +1 & 0.1 & -1 & 1 & -1 & 7.09 & 0.980 \\
\hline 3. & 4 & -1 & 0.2 & +1 & 1 & -1 & 14.0 & 0.978 \\
\hline 4. & 5 & +1 & 0.2 & +1 & 1 & -1 & 13.5 & 0.988 \\
\hline 5. & 4 & -1 & 0.1 & -1 & 3.5 & +1 & 6.7 & 0.982 \\
\hline 6. & 5 & +1 & 0.1 & -1 & 3.5 & +1 & 6.5 & 0.986 \\
\hline 7. & 4 & -1 & 0.2 & +1 & 3.5 & +1 & 12.8 & 0.991 \\
\hline 8. & 5 & +1 & 0.2 & +1 & 3.5 & +1 & 12.4 & 0.996 \\
\hline
\end{tabular}

Evaluated coefficients $b_{i}$ and $a_{i}$, according to equations (3), (4)

\begin{tabular}{|c|c|c|c|c|c|c|c|c|}
\hline Coefficient & $\boldsymbol{b}_{\mathbf{0}}$ & $\boldsymbol{b}_{\mathbf{1}}$ & $\boldsymbol{b}_{\mathbf{2}}$ & $\boldsymbol{b}_{\mathbf{3}}$ & $\boldsymbol{b}_{\mathbf{1 2}}$ & $\boldsymbol{b}_{\mathbf{1 3}}$ & $\boldsymbol{b}_{\mathbf{2 3}}$ & $\boldsymbol{b}_{\mathbf{1 2 3}}$ \\
\hline$J_{S S} \cdot 10^{-5}$ & 10.07 & -0.19 & 3.11 & -0.47 & -0.03 & 0.05 & -0.11 & -0.02 \\
\hline & $\boldsymbol{a}_{\mathbf{0}}$ & $\boldsymbol{a}_{\mathbf{1}}$ & $\boldsymbol{a}_{\mathbf{2}}$ & $\boldsymbol{a}_{\mathbf{3}}$ & $\boldsymbol{a}_{\mathbf{1 2}}$ & $\boldsymbol{a}_{\mathbf{1 3}}$ & $\boldsymbol{a}_{\mathbf{2 3}}$ & $\boldsymbol{a}_{\mathbf{1 2 3}}$ \\
\hline$r$ & 0.984 & 0.003 & 0.004 & 0.0044 & 0.00063 & -0.0009 & 0.0009 & -0.0004 \\
\hline
\end{tabular}

The developed polynomial equations with calculated regression coefficients gives an essential information on conjugated and non-conjugated effects of three independent variables $x_{1}(\mathrm{CFV}), x_{2}(\mathrm{TMP}), x_{3}(\mathrm{NaCl}$ concentration in the feed) on investigated system responses, $J_{S S}, r$ :

- the influence of CFV on steady-state permeate flux $J_{S S}$ is presented by coefficient $b_{1}$, $b_{12}, b_{13}$ and $b_{123}$; comparison of values of these coefficients indicates that non-conjugated coefficient $b_{2}$ characterizing influence on permeate flux is positive and decisive; positive value of coefficient means that with increasing operating parameter associated with this coefficient permeate flux increases; effect of the other two operating parameters, $\mathrm{CFV}\left(b_{1}\right)$ and $\mathrm{NaCl}$ concentration $\left(b_{3}\right)$ is less significant,

- the effect of the tested operating parameters on oil rejection coefficient is irrelevant due to the very high values in the range of 0.974-0.996.

The impact of independent variables on investigated system response (permeate flux $J_{v}$ ) are presented graphically in Figures $2 \mathrm{a}, \mathrm{b}$.

The data presented in Figure $2 \mathrm{a}$ and $2 \mathrm{~b}$ confirm the conclusions of the analysis of significance of regression coefficients of polynomial equation. The experimental results of $J_{S S}$ obtained for experiments No. 3, 4, 7 and 8 for TMP $=0.2 \mathrm{MPa}$ are about two fold higher than steady-state permeate fluxes for experiments with TMP $=0.1 \mathrm{MPa}$. 

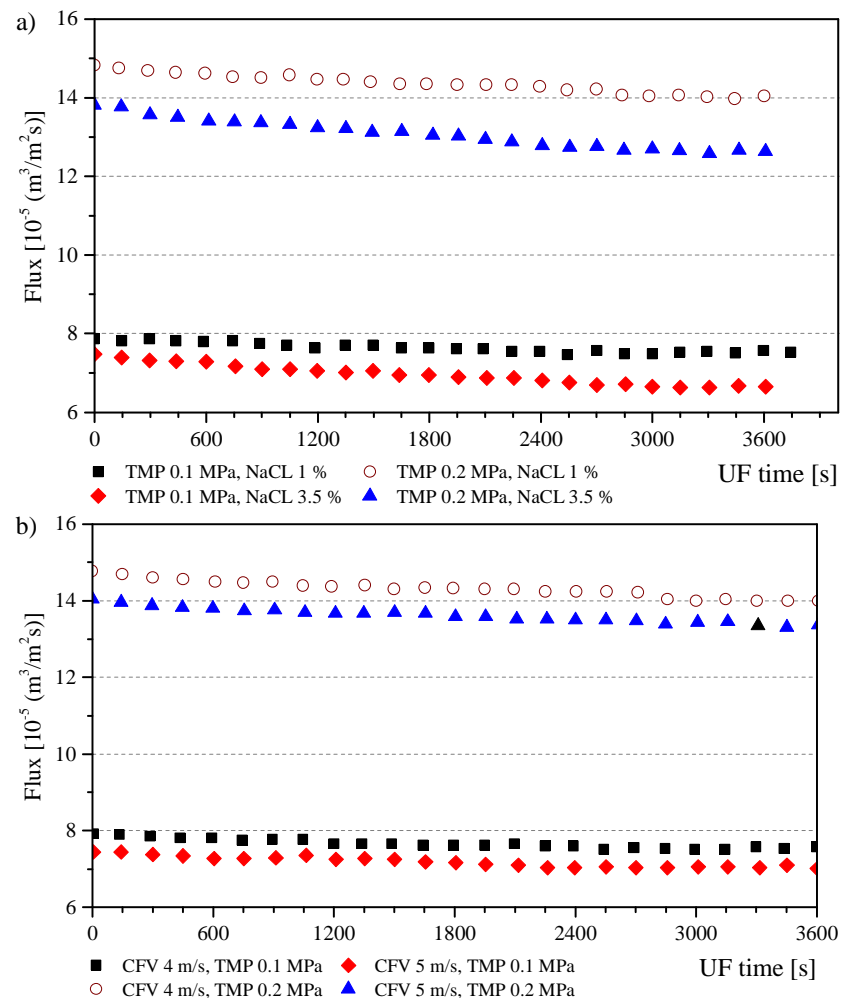

Fig. 2. Experimental flux versus time for ceramic membrane $300 \mathrm{kDa}$ in ultrafiltration of model oil-in water solution

\section{Resistance-in-series analysis}

Using the resistance-in-series model and equations (5)-(10) the values of transport resistances were obtained (Table 6). That would help to identify whether the process is membrane resistance-limited or fouling limited. Moreover, that would help to find which kind of fouling, reversible or irreversible is responsible for permeate flux decline with ultrafiltration time.

Table 6 Experimental and calculated results of transport resistances for investigated system: $300 \mathrm{kDa}$ ceramic membrane oil-water- $\mathrm{NaCl}$ solutions; oil content in the feed $500 \mathrm{ppm}$

\begin{tabular}{|c|c|c|c|c|c|c|c|c|c|c|c|}
\hline \multirow{2}{*}{ Exp. } & $\mathbf{C F V}$ & $\mathbf{T M P}$ & $\boldsymbol{C}_{\text {NaCl }}$ & $\boldsymbol{R}_{\boldsymbol{T}}$ & $\boldsymbol{R}_{\boldsymbol{F}}$ & $\boldsymbol{R}_{\boldsymbol{R} F}$ & $\boldsymbol{R}_{\boldsymbol{I F}}$ & $\boldsymbol{R}_{M}$ & $\boldsymbol{J}_{S S}$ & $\boldsymbol{J}_{W 1}$ & $\boldsymbol{J}_{\boldsymbol{W} \mathbf{2}}$ \\
\cline { 2 - 14 } & {$[\mathbf{m} / \mathbf{s}]$} & {$[\mathbf{M P a}]$} & {$[\mathbf{\%}]$} & \multicolumn{6}{|c|}{$[\mathbf{1 0} \mathbf{1}(\mathbf{1} / \mathbf{m})]$} & \multicolumn{3}{|c|}{$\left[\mathbf{1 0}^{-\mathbf{5}}\left(\mathbf{m}^{\mathbf{3}} /\left(\mathbf{m}^{\mathbf{2}} \cdot \mathbf{s}\right)\right]\right.$} \\
\hline 1. & 4 & 0.1 & 1 & 1.32 & 0.41 & 0.34 & 0.07 & 0.91 & 7.55 & 10.95 & 10.5 \\
\hline 2. & 5 & 0.1 & 1 & 1.41 & 0.50 & 0.35 & 0.15 & 0.91 & 7.09 & 10.95 & 9.45 \\
\hline 3. & 4 & 0.2 & 1 & 1.43 & 0.29 & 0.21 & 0.08 & 1.14 & 14.0 & 17.4 & 16.0 \\
\hline 4. & 5 & 0.2 & 1 & 1.48 & 0.34 & 0.27 & 0.07 & 1.14 & 13.5 & 16.4 & 15.4 \\
\hline 5. & 4 & 0.1 & 3.5 & 1.49 & 0.58 & 0.49 & 0.09 & 0.91 & 6.7 & 10.95 & 9.9 \\
\hline 6. & 5 & 0.1 & 3.5 & 1.54 & 0.63 & 0.49 & 0.14 & 0.91 & 6.5 & 10.95 & 9.4 \\
\hline 7. & 4 & 0.2 & 3.5 & 1.56 & 0.42 & 0.32 & 0.1 & 1.14 & 12.8 & 17.4 & 13.9 \\
\hline 8. & 5 & 0.2 & 3.5 & 1.61 & 0.47 & 0.39 & 0.08 & 1.14 & 12.4 & 16.4 & 13.6 \\
\hline
\end{tabular}


Graphical presentation of the effect of process parameters on transport resistances are given in Figure $3 \mathrm{a}$ and $3 \mathrm{~b}$.

It is visible from Table 6 and Figure $3 a$ and $3 b$ that for investigated system ultrafiltration process is membrane resistance-limited. The highest value of total resistance, $R_{T}$ was obtained for higher transmembrane pressure $(\mathrm{TMP}=0.2 \mathrm{MPa})$ and highest cross-flow velocity $(\mathrm{CFV}=5 \mathrm{~m} / \mathrm{s})$. At higher transmembrane pressure $(0.2 \mathrm{MPa})$, the increase of $\mathrm{CFV}$ from 4 to $5 \mathrm{~m} / \mathrm{s}$ lowers the $R_{T}$ value slightly. Increasing $\mathrm{NaCl}$ concentration in the feed from 1 to $3.5 \%$ has minor effect on transport resistance. The Table 6 and Figure $3 a$ and $3 b$ also show that for the most investigated experiments, reversible fouling resistance is bigger than irreversible one.
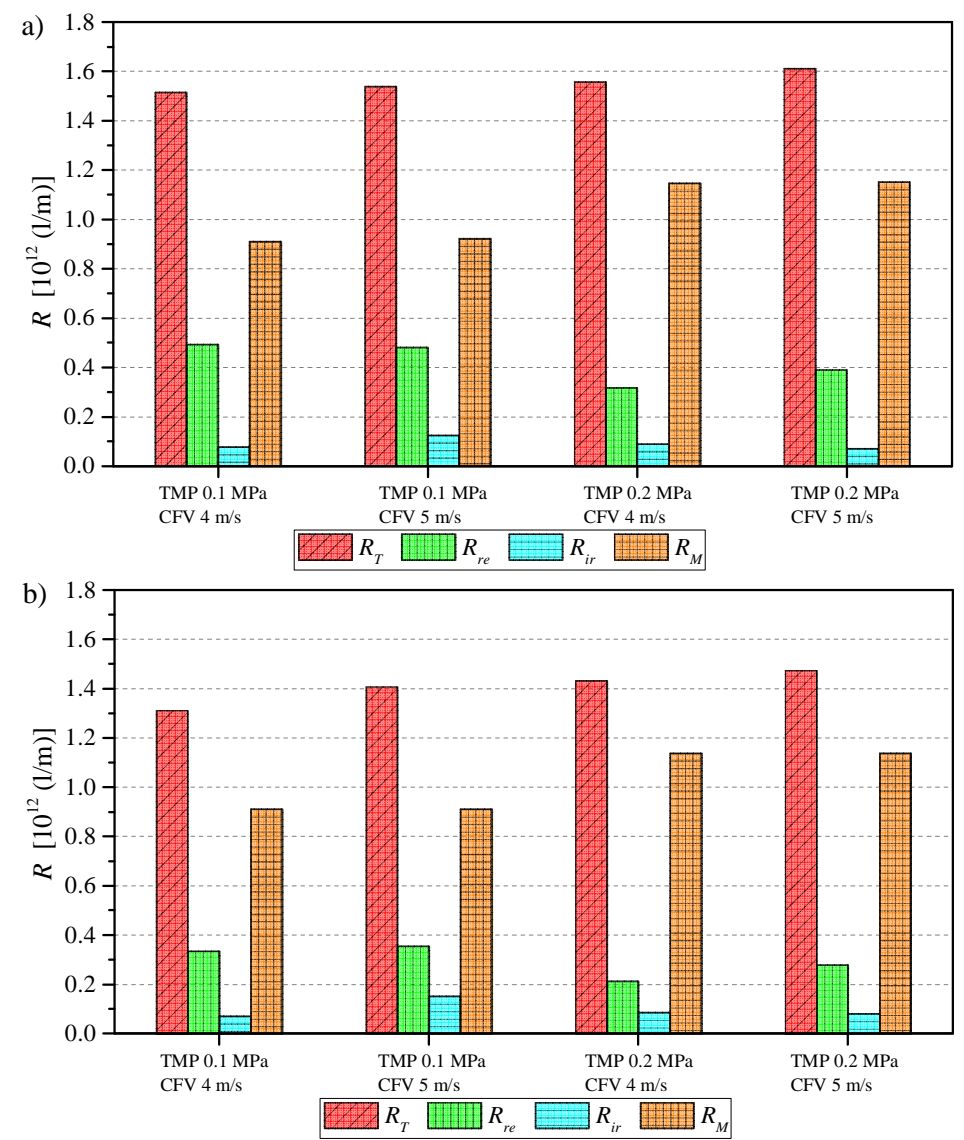

Fig. 3. Comparison of transport and membrane resistances for UF of oil emulsion: a) 500 ppm of oil concentration and $1 \% \mathrm{NaCl}$ and b) $500 \mathrm{ppm}$ of oil concentration and $3.5 \% \mathrm{NaCl}$

\section{Fouling mechanism analysis}

To identify the fouling mechanism during the ultrafiltration process of model oil-in-water solutions with addition of $\mathrm{NaCl}$, the parameters $k_{2}, k_{1.5}, k_{1.0}, k_{0}$ were estimated according to nonlinear approximation procedure using Mathcad 15.0 (PTC software). Each 
of the 8 experimental test runs were performed for each set by attaching ( $n=0, n=1.0$, $n=1.5, n=2.0$ ), matching to the steady-state value $J_{S S}$, measured experimentally (the obtained last three approximate values of $J_{V}$ ). Moreover in each experiment, values of $S D$ were calculated:

$$
S D=\sqrt{\frac{\sum\left(y_{\text {iexp }}-y_{\text {ical }}\right)^{2}}{l-1}}
$$

where: $S D$ - standard deviation, $l$ - total number of time intervals, $y_{\text {iexp }}$ - experimental data, $y_{\text {ical }}$ - calculated data.

The data obtained as a result of the analysis of each pore blocking mechanism for the ultrafiltration of oil-in-water solutions with addition of $\mathrm{NaCl}$ by ceramic $300 \mathrm{kDa}$ membrane are presented in Table 7.

The values of $k$ and values of standard deviation, estimated using equations (13-16) and (19)

\begin{tabular}{|c|c|c|c|c|c|c|c|c|c|c|c|}
\hline \multirow[t]{2}{*}{ Exp. } & \multirow[t]{2}{*}{$\begin{array}{l}\text { CFV } \\
{[\mathrm{m} / \mathrm{s}]}\end{array}$} & \multirow[t]{2}{*}{$\begin{array}{l}\text { TMP } \\
{[\mathrm{MPa}]}\end{array}$} & \multirow[t]{2}{*}{$\begin{array}{c}C_{\mathrm{NaCl}} \\
{[\%]}\end{array}$} & \multicolumn{2}{|c|}{$\begin{array}{l}\text { Complete pore } \\
\text { blocking, } n=2\end{array}$} & \multicolumn{2}{|c|}{$\begin{array}{c}\text { Internal pore } \\
\text { blocking, } \\
n=1.5\end{array}$} & \multicolumn{2}{|c|}{$\begin{array}{c}\text { Intermediate } \\
\text { pore blocking, } \\
n=1 \\
\end{array}$} & \multicolumn{2}{|c|}{$\begin{array}{c}\text { Cake formation, } \\
\qquad \begin{array}{c}n=0 \\
\end{array}\end{array}$} \\
\hline & & & & $\begin{array}{c}k_{2} \\
{\left[10^{-3}\right.} \\
(1 / \mathbf{s})]\end{array}$ & $\underset{\left[10^{-7}\right]}{S D}$ & $\begin{array}{c}k_{1.5} \\
{[\mathrm{~m} /} \\
\left.\left(\mathbf{m}^{1.5} \mathbf{s}^{0.5}\right)\right]\end{array}$ & $\begin{array}{c}S D \\
{\left[10^{-7}\right]}\end{array}$ & $\begin{array}{c}k_{1.0} \\
{\left[\mathrm{~m}^{2} / \mathrm{m}^{3}\right]}\end{array}$ & $\underset{\left[10^{-7}\right]}{S D}$ & $\begin{array}{c}k_{0} \\
{\left[10^{-4}\right.} \\
\left.\left(\mathbf{m}^{2} / \mathbf{m}^{3}\right)^{2} \mathbf{s}\right]\end{array}$ & $\underset{\left[10^{-7}\right]}{S D}$ \\
\hline 1. & 4 & 0.1 & 1 & 1.8 & 2.78 & 0.18 & 2.43 & 18.0 & 2.83 & 18.0 & 4.70 \\
\hline 2. & 5 & 0.1 & 1 & 4.0 & 5.87 & 0.5 & 7.52 & 40.0 & 6.24 & 40.0 & 4.76 \\
\hline 3. & 4 & 0.2 & 1 & 8.0 & 8.97 & 0.08 & 4.10 & 8.0 & 4.50 & 5.0 & 3.88 \\
\hline 4. & 5 & 0.2 & 1 & 1.3 & 4.07 & 0.13 & 4.96 & 11.0 & 4.90 & 11.0 & 7.32 \\
\hline 5. & 4 & 0.1 & 3.5 & 1.5 & 4.70 & 0.15 & 3.70 & 15.0 & 5.42 & 18.0 & 8.43 \\
\hline 6. & 5 & 0.1 & 3.5 & 1.2 & 5.33 & 0.12 & 3.61 & 12.0 & 6.54 & 14.7 & 9.94 \\
\hline 7. & 4 & 0.2 & 3.5 & 1.4 & 5.92 & 0.12 & 5.87 & 12.0 & 6.54 & 10.0 & 7.07 \\
\hline 8. & 5 & 0.2 & 3.5 & 1.8 & 5.92 & 0.18 & 6.95 & 18.0 & 8.20 & 13.0 & 7.40 \\
\hline
\end{tabular}

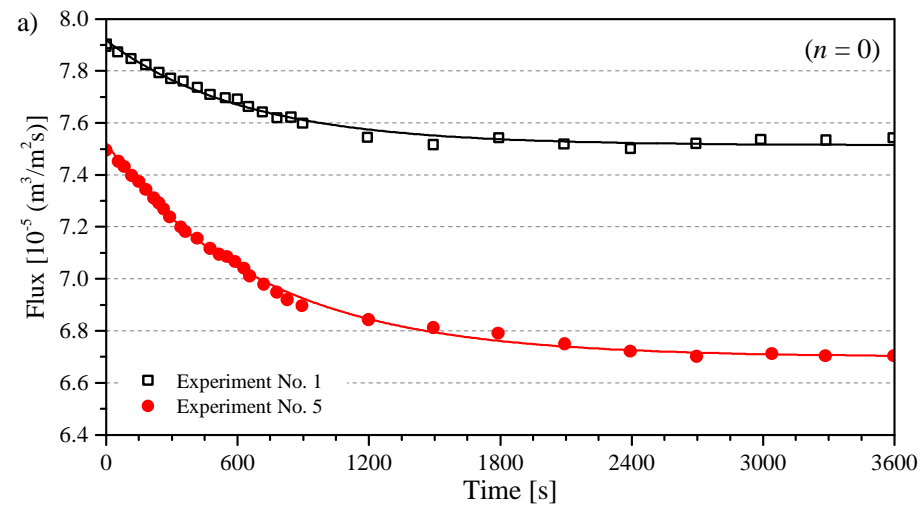



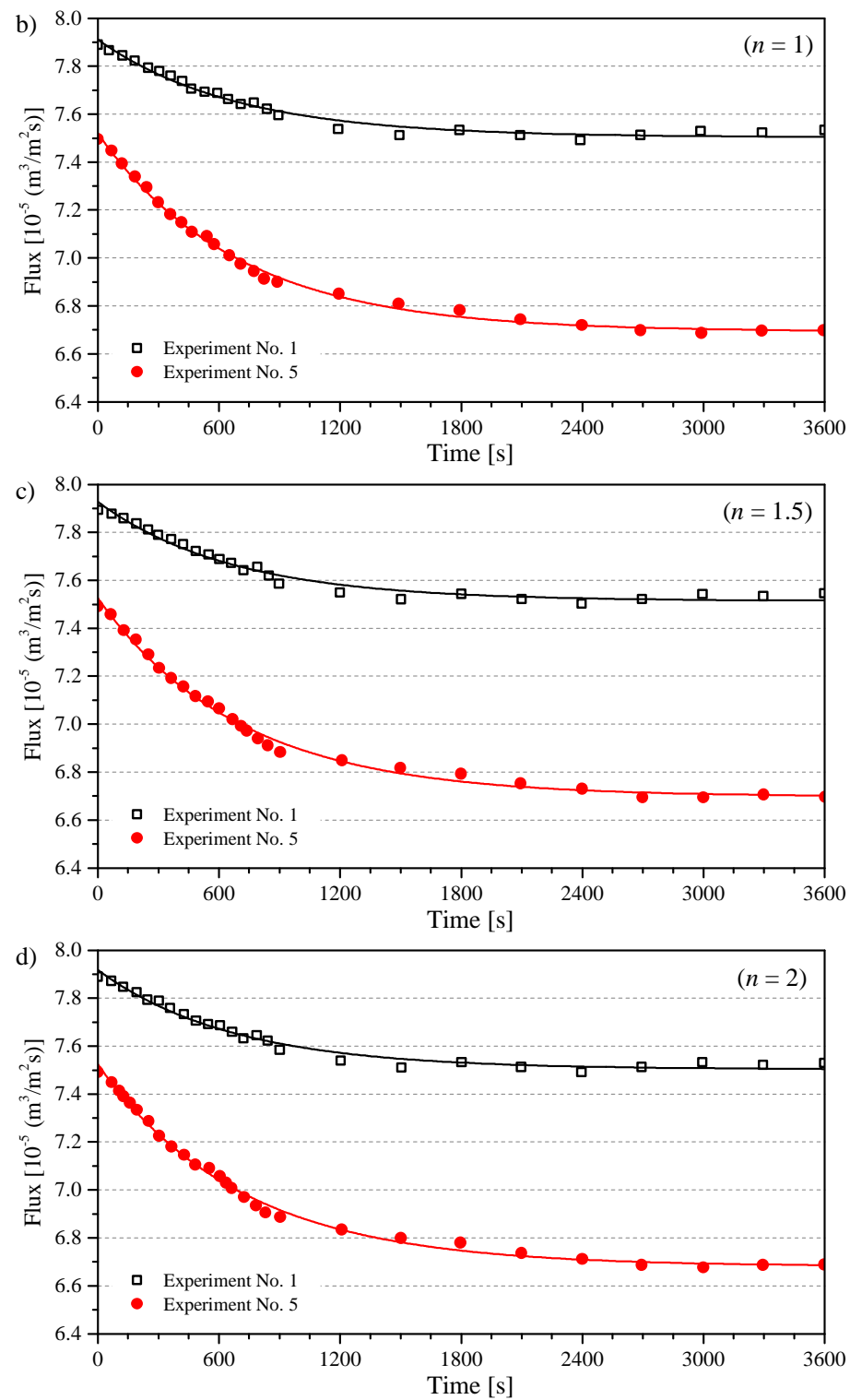

Fig. 4. Experimental and approximated values of permeate flux the experiments No. 1 (upper lines) and No. 5 (lower lines) for analyzed pore blocking mechanisms: a) cake formation, b) intermediate pore blocking, c) internal pore blocking, d) complete pore blocking

Figure 4a-d shows the results of nonlinear regression for each pore blocking model for experiments no 1 and 5. As shown in this figure all mathematical models well describe experimental data, because calculated from equation (19), standard deviation, represents very small values of the order of $10^{-7}$. It means that in investigated system more than one fouling mechanism is involved. 
However, Table 7 shows that the lowest value of standard deviation were obtained for fouling model with $n=1.5$. Due to the internal pore blocking model was the best representation for the experiments $1,5,6,7$. Furthermore, the cake formation model was the farthest away from experimental data, particularly for experiments with higher salt concentration in the feed (Table 7).

Figure 4a-d demonstrates that the differences between the experimental data and pore blocking models are quite small for all presented experiments. However for the ultrafiltration process of model oil-in-water- $\mathrm{NaCl}$ emulsion, the internal pore blocking model has a slight advantage (Fig. 4c). Considering, the evaluated coefficients, $k$ the complete pore blocking model is closer to the experimental data (Fig. 4d).

\section{Conclusions}

The paper presents a comprehensive analysis of the behaviour of $300 \mathrm{kDa}$ ceramic membrane in the process of ultrafiltration of oil emulsion in saline water. On the basis of the obtained experimental results and theoretical analysis the following conclusions can be made:

- The application of the $2^{3}$ experimental design method to perform ultrafiltration experiments and analysis of the effect of operating parameters on membrane permeability and selectivity showed that transmembrane pressure, TMP is a decisive operating parameter; $J_{S S}$ increases approximately two-fold with increase of 0.1 to $0.2 \mathrm{MPa}$; at the same time it was observed that oil rejection practically does not depend on the tested operating parameters in the studied ranges; ceramic $300 \mathrm{kDa}$ membrane reject oil emulsions in saline water on the level above 0.98 .

- The resistance-in-series analysis showed that ultrafiltration process of oil emulsion in saline water is membrane resistance-limited with external reversible fouling responsible to a large extent for flux decline vs ultrafiltration time.

- The analysis of results of experimental permeate flux vs time in the light of fouling mechanism models indicated that for $300 \mathrm{kDa}$ ceramic membrane no single behavior was representative; within the investigated ranges of three main ultrafiltration parameters, there are 3 models with good representation of fouling mechanism, i.e.: complete $(n=2)$, internal $(n=1.5)$ and intermediate $(n=1.0)$ pore blocking mechanism (Table 7).

- It means that ceramic membrane fouling by oil emulsions in saline water followed a sequence of mechanisms with an initial flux decline due to internal pore blocking mechanism, followed by complete pore blocking with subsequent intermediate pore blocking finally it should be pointed out that both analysis, resistance-in-series analysis as well as fouling mechanism identification, lead to consistent conclusions; first analysis demonstrated that $R_{R F}>R_{I F}$, what means that membrane fouling is external type; two identified pore blocking mechanisms (complete and intermediate) are also external types.

\section{References}

[1] Abadi SRH, Sebzari MR, Hemati M, Rekabdar F, Mohammadi T. Ceramic membrane performance in microfiltration of oily wastewater. Desalination. 2011;265:222-228. DOI: 10.1016/j.desal.2010.07.055. 
[2] Ebrahimi M, Willershausen D, Ashaghi KS, Engel L, Placido L, Mund P, et al. Investigations on the use of different ceramic membranes for efficient oil-field produced water treatment. Desalination. 2010;250(3):991-996. DOI: 10.1016/j.desal.2009.09.088.

[3] Jamaly S, Giwa A, Hasan SW. Recent improvements in oily wastewater treatment: Progress, challenges, and future future oportunities. J Environ Sci. 2015;(37):15-30. DOI: 10.1016/j.jes.2015.04.011.

[4] Ebenezer TI, Chen GZ. Produced water treatment technologies. Int J Low-Carbon Technol. 2014;9(3):157-177. DOI: 10.1093/ijlct/cts049

[5] Yu L, Han M, He F. A review of treating oily wastewater. Arab J Chem. 2017;10:1913-1922. DOI: 10.1016/j.arabjc.2013.07.020.

[6] Weschenfelder SE, Fonseca MJC, Borges CP, Campos JC. Application of ceramic membranes for water management in offshore oil production platforms: Process design and economics. Sep Purif Technol. 2016;171:214:220. DOI: 10.1016/j.seppur.2016.07.040.

[7] Bodzek M. Inorganic micropollutants removal by means of membrane processes - state of the art. Ecol Chem Eng S. 2016;23(2):285-295. DOI: 10.2478/eces-2013-0044.

[8] Brunetti A, Macedonio F, Barbieri G, Drioli E. Membrane engineering for environmental protection and sustainable industrial growth: Options for water and gas treatment. Environ Eng Res. 2015;20(4):307-328. DOI: 10.4491/eer.2015.074.

[9] Lin B, Lin CY, Jong TC. Investigation of strategies to improve the recycling effectiveness of waste oil from fishing vessels. Marine Policy. 2007;31:415-420. DOI: 10.1016/j.marpol.2007.01.004.

[10] Tanudjaja HJ, Chejase ChA, Tarabara VV, Fane AG, Chew JW. Membrane-based separation of oily wastewater: A practical perspective. Water Res. 2019;156:347-365. DOI: 10.1016/j.watres.2019.03.021.

[11] Abdelrasoul A, Doan H, Lohi A, Cheng CH. Mass Transfer Mechanisms and Transport Resistances in Membrane Separation Process. Chapter 2 In: Mass Transfer - Advancement in Process Modelling. London: IntechOpen; 2015: 15-40. DOI: 10.5772/60866.

[12] Dabestani S, Arcot J, Chen V. Protein recovery from potato processing water: Pre-treatment and membrane fouling minimization. J Food Eng. 2017;195:85-96. DOI: 10.1016/j.jfoodeng.2016.09.013.

[13] Brião VB, Tavares CRG. Pore blocking mechanism for the recovery of milk solids from dairy wastewater by ultrafiltration. Braz J Chem Eng. 2015;29(2):393-407. DOI: 10.1590/S0104-66322012000200019.

[14] Ahmadun FR, Pendashteh A, Abdullah LC, Biak DRA, Madaeni SS, Abidin ZZ. Review of technologies for oil and gas produced water treatment. J Hazard Mater. 2009;170:530-551. DOI: 10.1016/j.jhazmat.2009.05.044.

[15] Padaki M, Surya Murali R, Abdullah MS, Misdan N, Moslehyani A, Kassim MA, et al. Membrane technology enhancement in oil-water separation. A review. Desalination. 2015;357:197-207. DOI: 10.1016/j.desal.2014.11.023.

[16] Świerczyńska A, Bohdziewicz J, Puszczało E. Treatment of industrial wastewater in the sequential membrane bioreactor. Ecol Chem Eng. S. 2016;23(2):285-295. DOI: 10.1515/eces-2016-0020.

[17] Tomczak E, Blus M. Characteristics of polymeric ultrafiltration membranes produced with the use of graphene oxide. Ecol Chem Eng S. 2018;25(3):419-429. DOI: 10.1515/eces-2018-0029.

[18] Munirasu S, Abu Haija M, Banat F. Use of membrane technology for oil field and refinery produced water treatment - A review. Process Safety Environ Protect. 2016;100:173-202. DOI: 10.1016/j.psep.2016.01.010.

[19] Ghidossi R, Veyret D, Scotto JL, Jalabert T, Moulin P. Ferry oily wastewater treatment. Sep Purif Technol. 2009;4:296-303. DOI: 10.1016/j.seppur.2008.10.013.

[20] Sun Ch, Leiknes T, Weitzenböck J, Thorstensen B. Development of an integrated shipboard wastewater treatment system using biofilm-MBR. Sep Purif Technol. 2010;75:22-31. DOI: 10.1016/j.seppur.2010.07.005.

[21] Hesampour M, Krzyzaniak A, Nyström M. The influence of different factors on the stability and ultrafiltration of emulsified oil in water. J Membr Sci. 2008;325(1):199-208. DOI: 10.1016/j.memsci.2008.07.048.

[22] Abbasi M, Mirfendereski M, Nikbakht M, Golshenas M, Mohammadi T. Performance study of mullite and mullite-alumina ceramic MF membranes for oily wastewaters treatment. Desalination. 2010;259(1-3):169-178. DOI: 10.1016/j.desal.2010.04.013.

[23] Hua FL, Tsang YF, Wang YJ, Chan SY, Chua H, Sin SN. Performance study of ceramic microfiltration membrane for oily wastewater treatment. Chem Eng J. 2007;128(2-3):169-175. DOI: 10.1016/j.cej.2006.10.017.

[24] Zhang H, Zhong Z, Xing W. Application of ceramic membranes in the treatment of oilfield-produced water: Effects of polyacrylamide and inorganic salts. Desalination. 2013;309:84-90. DOI: 10.1016/j.desal.2012.09.012. 
[25] Matos M, Gutiérrez G, Lobo A, Coca J, Pazos C, Benito JM. Surfactant effect on the ultrafiltration of oil-in-water emulsions using ceramic membranes. J Membr Sci. 2016;520:749-759. DOI: 10.1016/j.memsci.2016.08.037.

[26] Pendashteh AR, Abdullah LCh, Fakhru'l-Razia A, Madaeni SS, Abidina ZZ, Radiah D, et al. Evaluation of membrane bioreactor for hypersaline oily wastewater treatment. Process Safety Environ Protect. 2012;90:45-50. DOI: 10.1016/j.psep.2011.07.006.

[27] Tomczak E, Kamiński W, Ćwirko K. Two-level factorial experiments in the ultrafiltration of oil - water emulsions. Desalin Water Treat. 2018;128:119-124. DOI: 10.5004/dwt.2018.22625.

[28] Freeman LJ, Ryan AG, Kensler JLK, Dickinson RM, Vining GG. A tutorial on the planning of experiments. Quality Eng. 2013;25:315-332. DOI: 10.1080/08982112.2013.817013.

[29] Chang, I-S, Kim S-N. Wastewater treatment using membrane filtration - effect of biosolids concentration on cake resistance. Process Biochem. 2005;40:1307-1314. DOI: 10.1016/j.procbio.2004.06.019.

[30] Bowen R, Calvo JI, Hernández A. Steps of membrane blocking in flux decline during protein microfiltration. J Membr Sci. 1995;101:153-165. DOI: 10.1016/0376-7388(94)00295-A.

[31] Iritani E, Katagiri N. Developments of blocking filtration model in membrane filtration. KONA. Powder Particle J. 2016;33:179-202. DOI: 10.14356/kona.2016024.

[32] Field RW, Wu D, Howell JA, Gupta BB. Critical flux concept for microfiltration fouling. J Membr Sci. 1995;100:259-272. DOI: 10.1016/0376-7388(94)00265-Z.

[33] Hwang K, Lin T. Effect of morphology of polymeric membrane on the performance of cross-flow microfiltration. J Membr Sci. 2002;199:41-52. DOI: 10.1016/S0376-7388(01)00675-5.

[34] Chang I-S, Le Clech P, Jefferson B, Judd S. Membrane fouling in membrane bioreactors for wastewater treatment. J Environ Eng. 2002;128(1):1018-1029. DOI: 10.1061/(ASCE)0733-9372(2002)128:11(1018). 